\title{
The Small GTPase CsRAC1 Is Important for Fungal Development and Pepper Anthracnose in Colletotrichum scovillei
}

\author{
Noh-Hyun Lee', Teng Fu', Jong-Hwan Shin ${ }^{1}$, Yong-Won Song', Dong-Cheol Jang ${ }^{\mathbf{2}}$, and Kyoung Su Kim (iD ${ }^{1 *}$ \\ ${ }^{I}$ Division of Bio-Resource Sciences, BioHerb Research Institute, and Interdisciplinary Program in Smart Agriculture, \\ Kangwon National University, Chuncheon 24341, Korea \\ ${ }^{2}$ Department of Horticulture, Kangwon National University, Chuncheon 24341, Korea
}

(Received on September 9, 2021; Revised on October 27, 2021; Accepted on October 31, 2021)

The pepper anthracnose fungus, Colletotrichum scovillei, causes severe losses of pepper fruit production in the tropical and temperate zones. RAC1 is a highly conserved small GTP-binding protein in the Rho GTPase family. This protein has been demonstrated to play a role in fungal development, and pathogenicity in several plant pathogenic fungi. However, the functional roles of RAC1 are not characterized in $C$. scovillei causing anthracnose on pepper fruits. Here, we generated a deletion mutant ( $\triangle$ Csrac1) via homologous recombination to investigate the functional roles of $\operatorname{CsR} A C 1$. The $\triangle C$ srac1 showed pleiotropic defects in fungal growth and developments, including vegetative growth, conidiogenesis, conidial germination and appressorium formation, compared to wild-type. Although $\triangle C$ Sracl was able to develop appressoria, it failed to differentiate appressorium pegs. However, $\triangle C$ Csracl still caused anthracnose disease with significantly reduced rate on wounded pepper fruits. Further analyses revealed that $\triangle C$ Srac1 was defective in tolerance to oxidative stress and suppression of host-defense genes. Taken together, our results suggest that $C s R A C 1$ plays essential roles in

\section{*Corresponding author}

Phone) +82-33-250-6435, FAX) +82-33-259-5558

E-mail)kims@kangwon.ac.kr

ORCID

Kyoung Su Kim

http://orcid.org/0000-0002-0827-0844

Handling Editor : Jungkwan Lee

(c) This is an Open Access article distributed under the terms of the Creative Commons Attribution Non-Commercial License (http:// creativecommons.org/licenses/by-nc/4.0) which permits unrestricted noncommercial use, distribution, and reproduction in any medium, provided the original work is properly cited.

Articles can be freely viewed online at www.ppjonline.org. fungal development and pathogenicity in $C$. scovilleipepper fruit pathosystem.

Keywords : Colletotrichum scovillei, fruit anthracnose, Rac1 GTPase

Chili Peppers (Capsicum annuum L.) is one of the most economically important vegetables around the world (Giacomin et al., 2020; Kim et al., 2014; Oo et al., 2017). According to estimates in 2019, peppers (dry and green) were produced about 42.2 million tons in the world (Food and Agriculture Organization of the United Nations, 2021). Although technologies regarding breeding and cultivation have largely improved, the production of peppers is still hindered by many phytopathogens (Ali et al., 2016). Among those, the anthracnose caused by fungal species from Colletotrichum genus, is well known as one of the most devastating fungal diseases on peppers (Giacomin et al., 2020). In the tropical and temperate zones, Colletotrichum scovillei, belonging to Colletotrichum acutatum species complex, is a dominant pathogen for anthracnose on pepper fruits (Caires et al., 2014; Khalimi et al., 2019; Oo et al., 2017; Toporek and Keinath, 2020). Similar to many other fungal pathogens, C. scovillei reproduces massive numbers of conidia, which serve as the major inoculum (Fu et al., 2021). The anthracnose by C. scovillei starts when conidia attach and adhere on the surface of pepper fruits (Fu et al., 2021). Upon recognition of chemical and physical signals from host, the conidia germinate and differentiate appressoria on the tips of germ tubes (Peres et al., 2005). Different to many appressorium-forming fungi, unmelanized appressoria of $C$. scovillei can penetrate host cuticle (Fu et al., 2021). At early stage of penetration process, dendroid structure is induced in the cuticle layer of 
pepper fruits (Fu et al., 2021; Liao et al., 2012). Following successful invasion in host epidermal cells, the fungus develops anthracnose disease with numerous acervuli on the typically sunken necrotic lesions (Oo and Oh, 2016). Although foliar diseases have been broadly studied, the development of fruit anthracnose remains investigated (Fu et al., 2021). Therefore, it is of interest to study the molecular mechanisms involved in C. scovillei-pepper fruit pathosystem.

The Rho (known as Ras homologous) GTPases, belonging to Ras superfamily of small GTPase, are a group of conserved GTP-binding enzymes that hydrolyze guanosine triphosphate (GTP) to guanosine triphosphate (GDP) (Van Aelst and D'Souza-Schorey, 1997). The Rho GTPases are commonly considered as molecular switches, which are turned on when the guanine nucleotide exchange factors accelerate the dissociation of the bound GDP, and turned off when the GTPase activating proteins stimulate the hydrolysis of GTP (Cherfils and Zeghouf, 2013). The Rho GTPases contains two functionally important elements: switch I and switch II, which display conformational changes during transition between GTP-bound (active) and GDP-bound (inactive) states (Fu et al., 2018; Smithers and Overduin, 2016). The inactive state GTPases are structurally disordered, while the active state GTPase are conformationally restrained, and bind their partners to trigger distinct downstream signaling pathways (Barthelmes et al., 2020). In the fungal kingdom, the Rho GTPases were firstly characterized in Saccharomyces cerevisiae, which contains six Rho GTPases (Rho1/RhoA, Rho2, Rho3, Rho4, Rho5 and CDC42) in the genome (Harris, 2011). The Rho GTPases regulate many aspects of cellular events during the growth and developments of $S$. cerevisiae, including cell polarity, cell wall integrity, exocytosis, polarized secretion, and mating projection (Gong et al., 2013; Robinson et al., 1999; Schmidt et al., 1997; Yoshida et al., 2009).

The plant pathogenic filamentous fungi do not contain the Rho5, but they possess another Rho GTPase Rac1, which is not homologous to yeast Rho5 (Harris, 2011). The existence of Rac1 in the plant pathogenic fungi rather than in yeast may be indicative that Rac1 plays important roles in the growth and development of filamentous fungi. To date, the roles of Rac1 have been functionally characterized in several filamentous fungi (Chen et al., 2008; Harris, 2011; Nesher et al., 2011; Rolke and Tudzynski, 2008; Tian et al., 2015; Virag et al., 2007). For example, deletion of Racl orthologs in the corn smut fungus Ustilago maydis and vascular wilt fungus Verticillium dahliae cause severe defects in polarized growth and virulence (Mahlert et al., 2006; Tian et al., 2015). Deletion of MgRacl in the rice blast fungus Magnaporthe grisea causes a dramatic reduction in conidiation and complete defect in appressorium formation and pathogenicity (Chen et al., 2008). The MgRac1 was found to interact with the PAK kinase (Chm1) and NADPH oxidases (Nox1 and Nox2), which are important for appressorium formation and penetration (Chen et al., 2008; Egan et al., 2007; Karnoub et al., 2004). These data reveal that the Rac1 plays essential roles in the developments and pathogenicity of plant pathogenic fungi.

The pepper anthracnose fungus, Colletotrichum scovillei, causes severe losses of pepper fruit production in the tropical and temperate zones. RAC1 is a highly conserved small GTP-binding protein in the Rho GTPase family. This protein has been demonstrated to play a role in fungal development, and pathogenicity in several plant pathogenic fungi. However, the functional roles of RAC1 are not characterized in C. scovillei causing anthracnose on pepper fruits. Here, we generated a deletion mutant ( $\triangle C$ Csracl) via homologous recombination to investigate the functional roles of CsRAC1. The $\triangle C$ sracl showed pleiotropic defects in fungal growth and developments, including vegetative growth, conidiogenesis, conidial germination and appressorium formation, compared to wild-type. Although $\triangle C s r a c 1$ was able to develop appressoria, it failed to differentiate appressorium pegs. However, $\Delta$ Csracl still caused anthracnose disease with significantly reduced rate on wounded pepper fruits. Further analyses revealed that $\Delta C s r a c 1$ was defective in tolerance to oxidative stress and suppression of host-defense genes. Taken together, our results suggest that CsRAC1 plays essential roles in fungal development and pathogenicity in C. scovillei-pepper fruit pathosystem.

In this study, we set out to investigate the functional roles of $C S R A C 1$ in the pepper fruit anthracnose fungus $C$. scovillei using a targeted gene deletion mutant $\triangle C$ sracl. Deletion of CsRACl resulted in pleiotropic defects in mycelial growth, conidiation, conidium morphology, conidial germination, and appressorium formation, compared to wild-type. $\triangle C s r a c 1$ failed to form appressorium pegs, even though it was able to differentiate appressoria. However, $\triangle C$ sracl still caused anthracnose disease with significantly reduced rate on wounded pepper fruits, which may be caused by defects in tolerance to oxidative stress and suppression of host-defense gene. Taken together, our results suggested that CsRACl is important for fungal growth, development, and pathogenicity in $C$. scovillei-pepper fruit pathosystem.

\section{Materials and Methods}

Fungal strains, culture conditions. In this study, Col- 
letotrichum scovillei wild-type strain $\mathrm{KC} 05$ and its transformants were routinely incubated on oatmeal agar (OMA; $50 \mathrm{~g}$ oatmeal and $15 \mathrm{~g}$ agar powder per liter) at $25^{\circ} \mathrm{C}$ with continuous light (Fu et al., 2021). Mycelia for extraction of genomic DNA and total RNA were grown in liquid complete media (CM, $10 \mathrm{~g}$ sucrose, $6 \mathrm{~g}$ casamino acid, and 6 $\mathrm{g}$ yeast extract per liter) for 2 days at $25^{\circ} \mathrm{C}$ with agitation (150 rpm) (Han et al., 2018). Fungal transformants were grown on transformation agar (TB3 agar, $200 \mathrm{~g}$ sucrose, $3 \mathrm{~g}$ casamino acid, $3 \mathrm{~g}$ yeast extract, $10 \mathrm{~g}$ glucose, and $8 \mathrm{~g}$ agar powder per liter) (Shin et al., 2019).

Phylogenetic analysis and sequence alignment. The sequences of CsRAC1 and its homologs were downloaded from National Center for Biotechnology Information (NCBI, http://www.ncbi.nlm.nih.gov) and Comparative Fungal Genomics Platform (CFGP, http://cfgp.riceblast. snu.ac.kr) (Fu et al., 2019). Phylogenetic relationship among CsRAC1 and others Rho GTPases were analyzed using MEGA 7.0 software. The identities between CsRAC1 and its homologs were analyzed using NCBI BLASTP (https://blast.ncbi.nlm.nih.gov/). Domain structures were predicted using InterPro Scan (http://www.ebi. ac.uk/interpro/), and visualized using Illustrator for Biological Sequences, version 1.0.3. Primers were designed using Primer Quest Design Tool (http://sg.idtdan.com/site).

Targeted deletion of CsRAC1 and generation of complemented strain. Targeted deletion constructs were generated according to a modified double joint PCR ( $\mathrm{Yu}$ et al., 2004). Each segment ( $1.5 \mathrm{~kb})$ corresponding to upstream and downstream of CsRAC1, was amplified using the primers $5 \mathrm{~F} / 5 \mathrm{R}$ and $3 \mathrm{~F} / 3 \mathrm{R}$ (Table 1 ). The $H P H$ cassette, used for selection marker, was amplified using the primers

Table 1. Primers used in this study

\begin{tabular}{ll}
\hline Primer & Sequence $\left(5^{\prime} \rightarrow 3^{\prime}\right)$ \\
\hline CsRAC1 & \\
$5 \mathrm{~F}$ & CTTCCGTTGCCTTGACTTCTATTGC \\
$5 \mathrm{R}$ & CCTCCACTAGCTCCAGCCAAGCCTTGGAGGGACAAGGAGAATTG \\
$3 \mathrm{~F}$ & GTTGGTGTCGATGTCAGCTCCGGAGAACATTTGGATTGGCGTTCAG \\
$3 \mathrm{R}$ & GAAGACGGAGAAGAAGGACAAA \\
$\mathrm{NF}$ & GCTTGGTCTGGTCTGTCTTC \\
NR & CTCCATCAACGCCCACTT \\
SF & TTGACTCTCTCGCCTACCTTA \\
SR & TCTTTGTGAGAGTGAGTGCTATC \\
RTF & GTCTGGGACTTTGGGATACTG \\
RTR & GAGGGACTCAAGGGTGTTG \\
PF & TTTCCCACCACCTTCAACAC \\
PR & GGTTCCGATGGCTGCATAAA \\
Hygromicin phophotransferase & \\
HPH_F & GGCTTGGCTGGAGCTAGTGGAGG \\
HPH_R & CTCCGGAGCTGACATCGACACCAAC \\
Capsicumannumm defense genes & \\
CaActin_F & AAGCTCTCCTTTGTTGCTGTT \\
CaActin_R & GACTTCTGGGCATCTGAATCT \\
CaHIR1_F & GACAAAGCTAATGAAGCATTCTAC \\
CaHIR1_R & GGTGTCGAAGTACTGGGTTACC \\
CaLRR1_F & GAATGCAACTCCGAAGGG \\
CaLRR1_R & CTGATAATCTATTACTATTCAATCTCA \\
CaPAL1_F & GGTTTTGGTGCAACATCACATAGGAG \\
CaPAL1_R & ATTGTCAAAGTTCTCTTAGCTACTTGGC \\
CaPik1_F & GGCTCTTGGTTCACTGGAAGATCATCTA \\
CaPik1_R & GCACAGTATCCATATGTACCCATCACTCTG \\
CaPR1_F & CAGGATGCAACACTCTGGTGG \\
CaPR1_R & ATCAAAGGCCGGTTGGTC \\
\hline
\end{tabular}


HPHF/HPHR from pBCATPH (Choi et al., 2009). Those three amplified PCR products were fused and amplified with the primers NF/NR (Table 1) to generate the deletion constructs. The protoplasts of wild-type C. scovillei were transformed with the deletion constructs. The obtained transformants were cultured on TB3 agar containing hygromycin B (Sigma, St. Louis, MO, USA). The transformants were then screened by using PCR the primers SF/ SR (Table 1). The target deletion mutants were confirmed by Southern blotting and reverse transcription polymerase chain reaction (RT-PCR). To generate a complemented strain (Csraclc), the target gene was amplified from the wild-type $C$. scovillei genome with primers NF/NR (Table 1). The amplicons were co-introduced into the protoplasts of $\Delta C s r a c 1$, with geneticin resistance gene amplified from pII99 vector with primers GenF/GenR (Han et al., 2015). Complemented strains were selected through screening PCR and confirmed by RT-PCR.

RNA isolation and gene expression analysis. Total RNA was extracted from fungal mycelia and infected pepper fruits using Easy-Spin (iNtRON Biotechnology, Seongnam, Korea). cDNA was synthesis using the SuperScript III First-strand Synthesis System (Invitrogen, Carlsbad, CA, USA) from the total RNA. To detect transcripts of $C s$ $R A C 1$ in the transformants, RT-PCR was performed in a 20 $\mu 1$ mixture containing $50 \mathrm{ng} / \mu \mathrm{l}$ cDNA, $20 \mathrm{U}$ Pfu Plus DNA polymerase (Elpis Bio, Daejeon, Korea) and 10 pmol forward/reverse primers (Fu et al., 2019). The $\beta$-tubulin gene was used as a control (Table 1). To analyze the gene expression, quantitative RT-PCR (qRT-PCR) was performed in a $10 \mu \mathrm{l}$ mixture containing $5 \mu \mathrm{l}$ HiPi Real-Time PCR $2 \times$ Master Mix (Elpis Bio), cDNA (25 ng/ $\mu \mathrm{l})$, and $0.5 \mu \mathrm{l}$ forward/reverse primers $(10 \mathrm{pmol} / \mu \mathrm{l})$, using StepOne RealTime PCR System (Applied Biosystems, Foster City, CA, USA). The qRT-PCR was performed in three-independent experiments with two replicates per experiment.

Phenotypic characterization of mutants. Potato dextrose agar (PDA; $39 \mathrm{~g}$ of potato dextrose agar per liter) and minimal media agar (MMA; $30 \mathrm{~g}$ of sucrose, $2 \mathrm{~g}$ of $\mathrm{NaNO}_{3}, 1$ $\mathrm{g}$ of $\mathrm{KH}_{2} \mathrm{PO}_{4}, 0.5 \mathrm{~g}$ of $\mathrm{MgSO}_{4} \cdot 7 \mathrm{H}_{2} \mathrm{O}, 0.5 \mathrm{~g}$ of $\mathrm{KCl}, 20 \mathrm{~g}$ of agar and $0.1 \mathrm{ml}$ trace element solution per liter) were used to investigate mycelia growth. Lactophenol blue was used to stain the mycelia. To evaluate mycelial growth under oxidative stress, mycelial agar plugs from MMA were inoculated onto complete medium agar (CMA; $10 \mathrm{~g}$ of sucrose, $6 \mathrm{~g}$ of yeast extract, $6 \mathrm{~g}$ of casamino acid, and $15 \mathrm{~g}$ of agar per liter) containing $\mathrm{H}_{2} \mathrm{O}_{2}$ and incubated without light for 5 days at $25^{\circ} \mathrm{C}$. For conidiation assay, mycelial agar plugs from MMA were inoculated onto V8 agar (V8A; V8 juice $80 \mathrm{ml}, 310 \mu \mathrm{l}$ of $10 \mathrm{~N} \mathrm{NaOH}, 15 \mathrm{~g}$ of agar per liter), and incubated for 5-day dark and 2-day light at $25^{\circ} \mathrm{C}$. Conidia were harvested with $5 \mathrm{ml}$ of distilled water and counted using hemocytometer. To evaluate conidial germination and appressorium formation, conidia from OMA cultures were harvested using $2 \mathrm{ml}$ distilled water, and then filtered through three layers of Miracloth (Calbiochem, San Diego, CA). Conidial suspensions were centrifuged at 5,000 rpm for $10 \mathrm{~min}$ for three times. Drops $(20 \mu \mathrm{l})$ of conidia suspensions $\left(5 \times 10^{4} / \mathrm{ml}\right)$ were placed on the hydrophobic surface of coverslips, and incubated in a humid plastic box at $25^{\circ} \mathrm{C}$. To investigate septation in mycelia, mycelial agar plugs from OMA were placed on the coverslips and incubated for 3 days in dark. The septa were stained with Calcofluor white (CFW), and observed using a fluorescent microscope (Carl Zeiss, Jena, Germany).

Pathogenicity assays. To perform plant infection assays, conidial suspension $\left(5 \times 10^{5} / \mathrm{ml}\right)$ were inoculated onto intact and wounded pepper fruits, and incubated in a humid plastic box at $25^{\circ} \mathrm{C}$ for 7 and 5 days, respectively. To evaluate appressorium formation and penetration, and dendroid structure formation, conidia suspension $\left(5 \times 10^{4} / \mathrm{ml}\right)$ were inoculated on intact pepper fruits, and incubated in humid plastic box at $25^{\circ} \mathrm{C}$. The samples were sliced from infected pepper fruits with a razor and observed using a light microscope. All of experiments were performed in three-independent experiments with three replicates per experiment.

\section{Results}

Phylogenetic analysis, domain prediction, and targeted gene deletion. The phylogenetic analysis showed that CsRAC1 from C. scovillei and other Rho GTPases from Colletotrichum gloeosporioides, Magnaporthe oryzae, Claviceps purpurea, Talaromyces marneffei, Neurospora crassa, and U. maydis were divided into six clades, which are $\mathrm{RHO} 1, \mathrm{RHO} 2, \mathrm{RHO} 3, \mathrm{RHO} 4, \mathrm{RAC1}$, and $\mathrm{CDC} 42$ clades (Fig. 1A). In the RAC1 clade, CsRACl was closely related to its homolog in C. gloeosporioides, but distantly related to its homolog in U. maydis. Domain predictions revealed that all RAC1 proteins in those fungi contain a small GTP-binding protein domain (IPR005225) (Fig. 1B), which includes five G motifs (G1 to G5) and two functional elements (switch I, switch II) (Fig. 1C). A NCBI BLASTP search indicated that CsRAC1 shares $98.49 \%$, $94.47 \%, 95.68 \%, 87.76 \%, 84.62 \%, 76.80 \%$ sequence identity with EQB58834.1, XP_003721025.1, KAG6135690.1, XP_002152535.1, XP_964519.3, and XP_011386548.1 
A

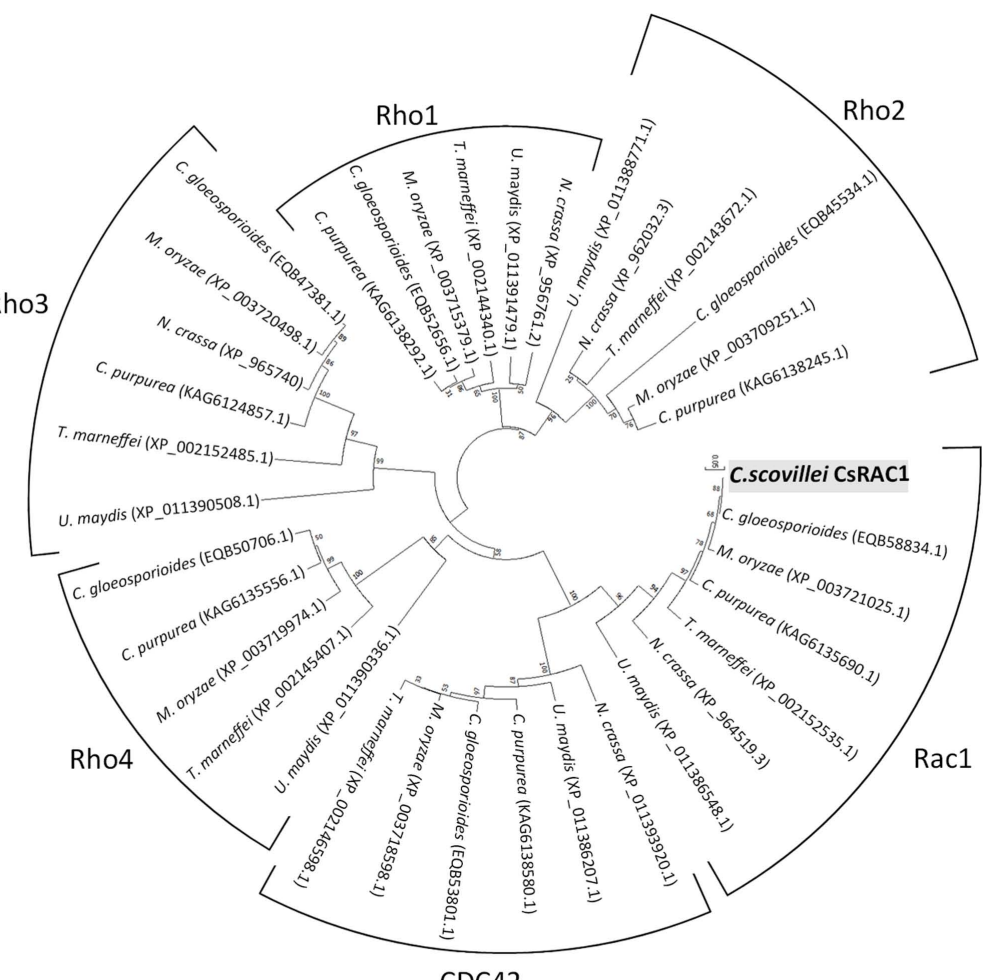

B

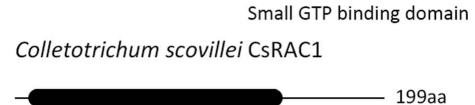

Colletotrichum gloeosporioides (EQB58834.1)

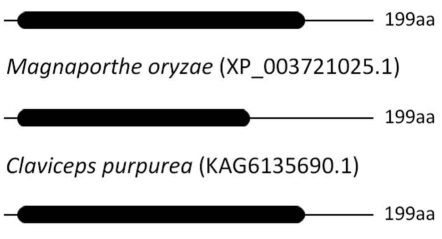

Talaromyces marneffei (XP_002152535.1)

Neurospora crassa (XP_964519.3)

Ustilago maydis (XP_011386548.1) - 199aa

C

CDC42

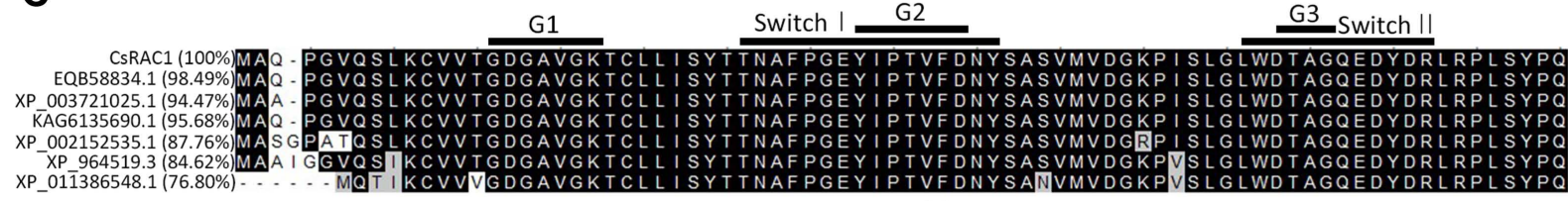

XP_011386548.1

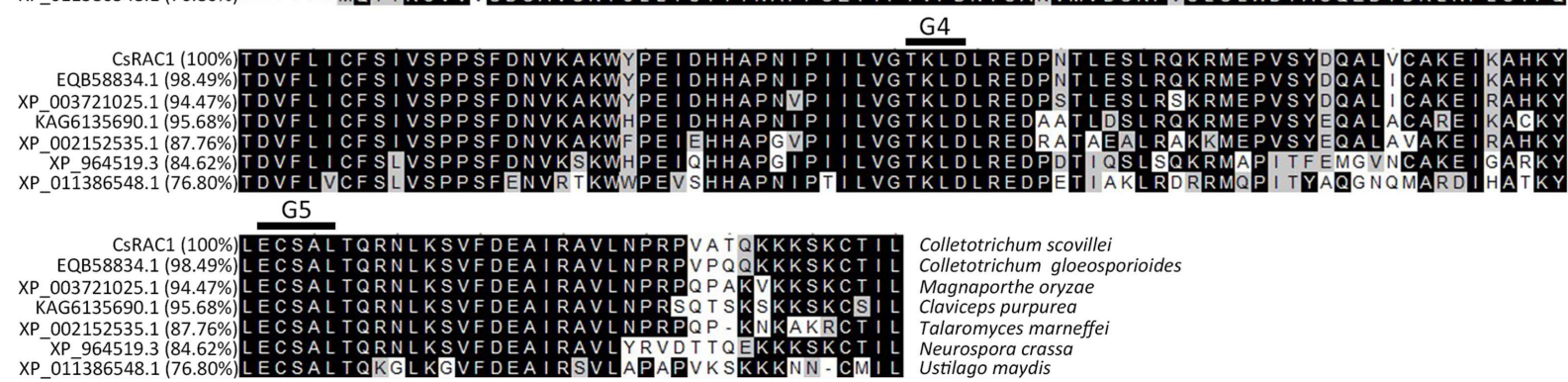

Fig. 1. Phylogenetic analysis, domain prediction, and sequence alignment. (A) Phylogenetic analysis of Rho GTPases in different fungi. The phylogentic tree was generated by neighbor-joining method with 1,000 boot straps using MEGA 7.0 software. (B) Domain prediction of CsRAC1 homologs in different fungi. Domian rediction using InterProScan revealed that all proteins contain a small GTPbinding protein domain (IPR005225). (C) Sequnece alignment of small GTP-binding protein domain among CsRAC1 homologs. The conserved amino acid sequences were marked with black shadow. The small GTP-binding protein domain contains conserved motifs, including switch I, switch II, G1, G2, G3, G4, and G5.

from C. gloeosporioides, M. oryzae, C. purpurea, $T$. marneffei, N. crassa, and U. maydis, respectively (Fig. 1C). These results suggest that CsRAC1 homologs are well-conserved in plant pathogenic fungi. To determine the role of $C s R A C 1$, we generate a targeted gene deletion mutant ( $\triangle$ Csracl) via homologous replacement (Fig. 2A). $\triangle C$ sracl was confirmed by Southern blotting and RT-PCR (Fig. 2B and C). To verify that the phenotypes of $\triangle C$ sracl were caused by deletion of $C s R A C 1$, we generated a complemented strain (Csraclc), which was verified by RTPCR (Fig. 2C).

Roles of CsRAC1 in mycelial growth and septation. To investigate the roles of $C s R A C 1$ in vegetative growth, we measured the diameter of colony growth. The colony diameter of wild-type was $41.7 \pm 0.6 \mathrm{~mm}$ and $35.3 \pm 0.6$ 
A

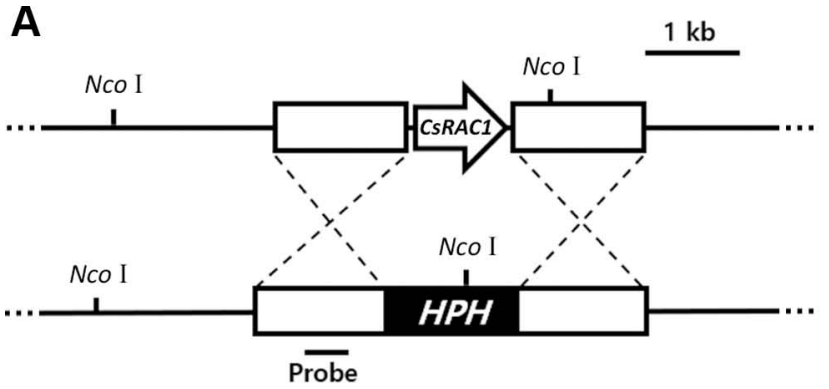

B

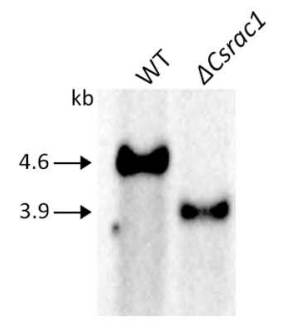

C

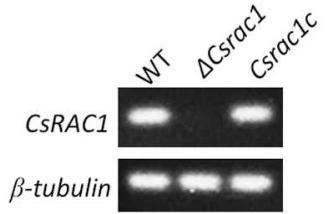

Fig. 2. Targeted gene deletion and verification of deletion mutant. (A) Targeted deletion of CsRACl. The CsRACl was replaced using $H P H$ cassette via homologous recombination. (B) Verification of $C s R A C l$ deletion using Southern blotting. Genomic DNA of wild-type and candidate mutants was digested with $\mathrm{Nco}$ I and hybridized to a specific probe. (C) Expresison of $C s R A C l$ in deletion mutant. Expresion of $C S R A C l$ was confirmed using reverse transcription polymerase chain reaction.

mm on PDA and MMA, respectively (Fig. 3A and B). however, $\triangle C$ sracl significantly reduced mycelial growth with colony diameters of $30.3 \pm 0.6 \mathrm{~mm}$ on PDA and 26.0 $\pm 1.0 \mathrm{~mm}$ on MMA (Fig. 3A and B). $\triangle$ Csracl was found to show more densely branched mycelia, compare to wildtype (Fig. 3A). The defect of mycelial growth was recovered in the Csraclc (Fig. 3A and B). These results suggest that $C s R A C 1$ is involved in mycelial growth of C. scovillei.
A

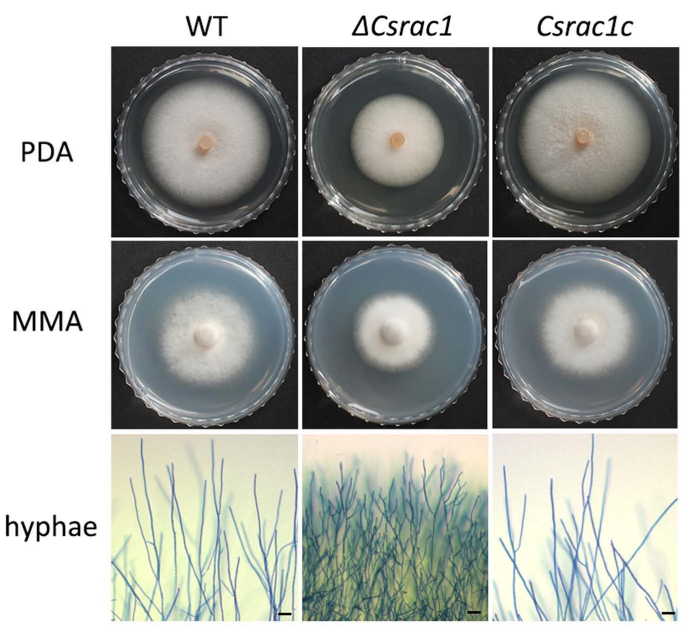

C

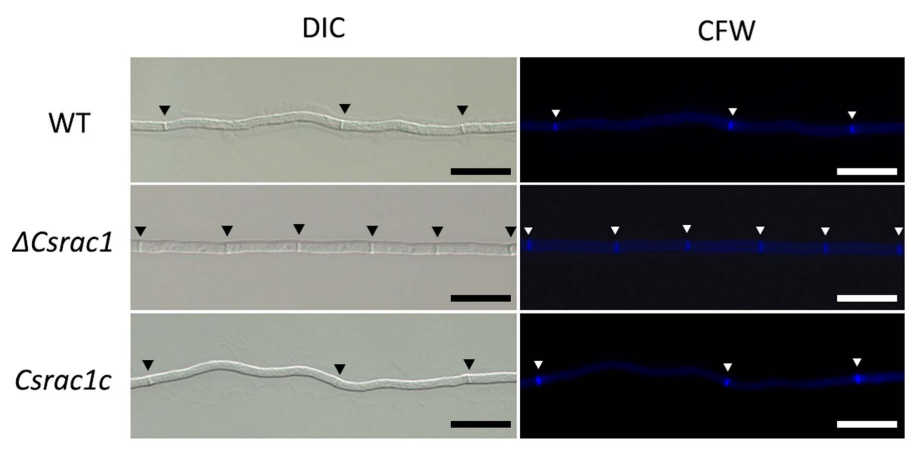

B

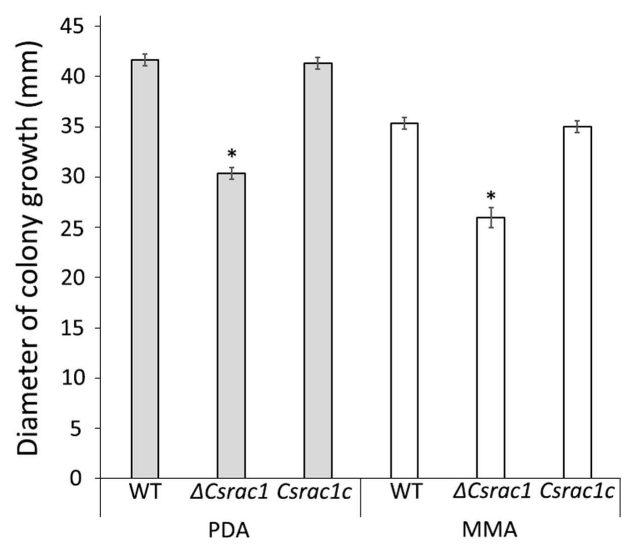

D

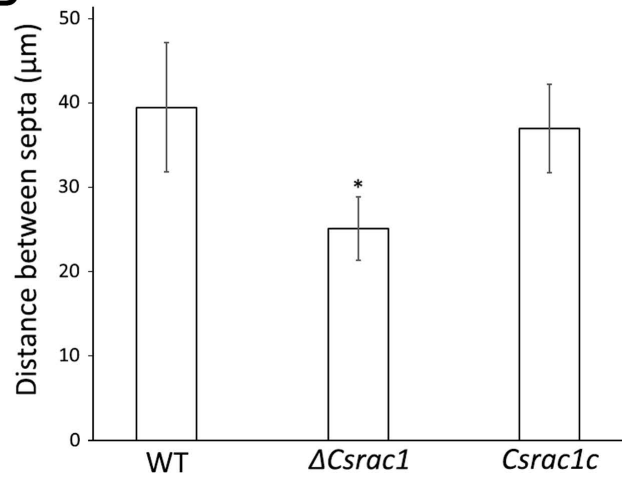

Fig. 3. Roles of CsRAC1 in mycelial growth and septation. (A, B) Evaluation of mycelial growth on potato dextrose agar (PDA) and minimal media agar (MMA). (A) Photographs of mycelail growth and hyphal tips were taken after 5 days. Scale bars $=20 \mu \mathrm{m}$. (B) Colony diameter was measured after 5 days. (C, D) Observation of septation in mycelia. (C) The mycelial septa were stained with Calcofluor white (CFW). DIC, differential interference contrast. (D) The average distance between septa was measured at least 50 mycelial compartments. Scale bars $=20 \mu \mathrm{m}$. Significant difference $(*)$ was analyzed by Duncan's test $(P<0.05)$. 
We next stained hyphae using CFW to observe their morphology and septation. The hyphal morphology of $\triangle C s r a c 1$ was found to be indistinguishable, whereas the average distance of the hyphal compartments of $\Delta \operatorname{Csracl}(25.1 \pm 3.7$ $\mu \mathrm{m})$ was significantly shorter than that of wild-type (39.5 $\pm 7.7 \mu \mathrm{m})$ and Csraclc $(37.0 \pm 5.2 \mu \mathrm{m})$ (Fig. 3C and D). These results suggest that $C s R A C 1$ is involved in growth and septation of hyphae in $C$. scovillei.

Roles of CsRAC1 in conidiation and conidium morphology. To determine whether CsRACl is involved in conidiation, we counted the conidia produced by $\triangle C s r a c l$. The result showed that $\triangle C$ sracl produced significantly less conidia, compared to wild-type and Csraclc (Fig. 4A),
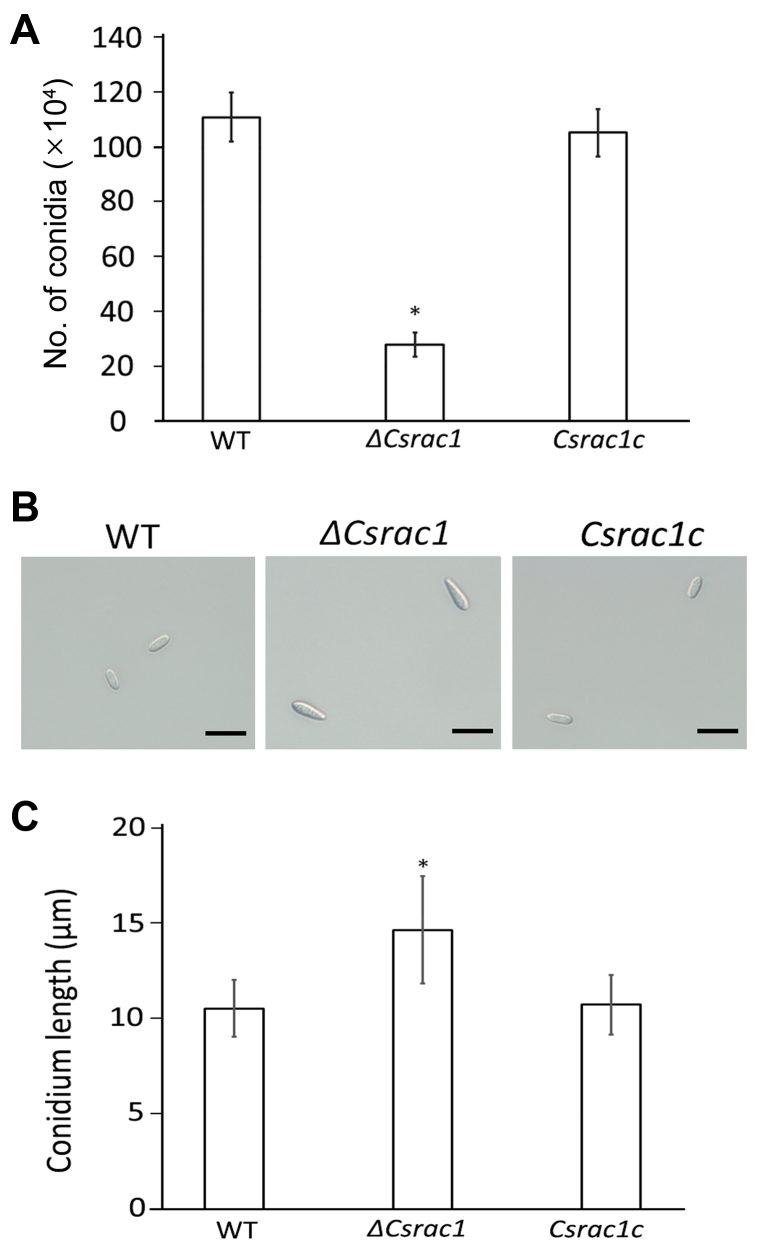

Fig. 4. Roles of $C S R A C 1$ in conidiogenesis. (A) Quantitative evaluation of conidiation. Conidia were collected with $5 \mathrm{ml}$ of distilled water from 7-day-old oatmeal agar (OMA). (B) Observation of conidium morphology. The conidia were collected from 7-day-old OMA. Scale bars $=20 \mu \mathrm{m}$. (C) Measurement of conidium length. The average length of conidia were measued from at least 50 conidia, collected from 7-day-old OMA. Significant difference $(*)$ was analyzed by Duncan's test $(P<0.05)$. suggesting that $C s R A C 1$ is associated with conidiation of $C$. scovillei. Notably, conidia produced by $\triangle C s r a c l$ exhibited abnormal shape, compared to the wild-type and Csraclc (Fig. 4B and C). The $\triangle C$ Sracl produced larger conidia with average length of $14.6 \pm 2.8 \mu \mathrm{m}$, which is longer than that of wild-type $(10.5 \pm 1.5 \mu \mathrm{m})$ and Csraclc $(10.7 \pm 1.6 \mu \mathrm{m})$. Furthermore, $\triangle C s r a c l$ conidia are one end acute, whereas the wild-type conidia are cylindrical to clavate shape (Fig. $4 \mathrm{~B})$. These results suggested that $C s R A C 1$ plays important roles in conidiogenesis.

Roles of CsRAC1 in appressorium formation. Because appressorium development is prerequisite for anthracnose disease by $C$. scovillei (Fu et al., 2021), we investigated whether CsRACl is involved in appressorium development on the hydrophobic surface of coverslips. After $5 \mathrm{~h}$, the germination rate of wild-type was $77.3 \pm 1.2 \%$, whereas only $22.7 \pm 3.1 \%$ of $\triangle C$ sracl conidia formed germ tube (Fig. 5). The defect in conidial germination was recovered in the Csraclc. After 16 h, $92.7 \pm 2.1 \%$ and $92.3 \pm 2.1 \%$ conidia of wild-type and $\mathrm{Csraclc}$ differentiated appressoria, respectively (Fig. 5). However, the appressorium formation rate was $42.3 \pm 5.5 \%$. These results suggest that $C s R A C 1$ is
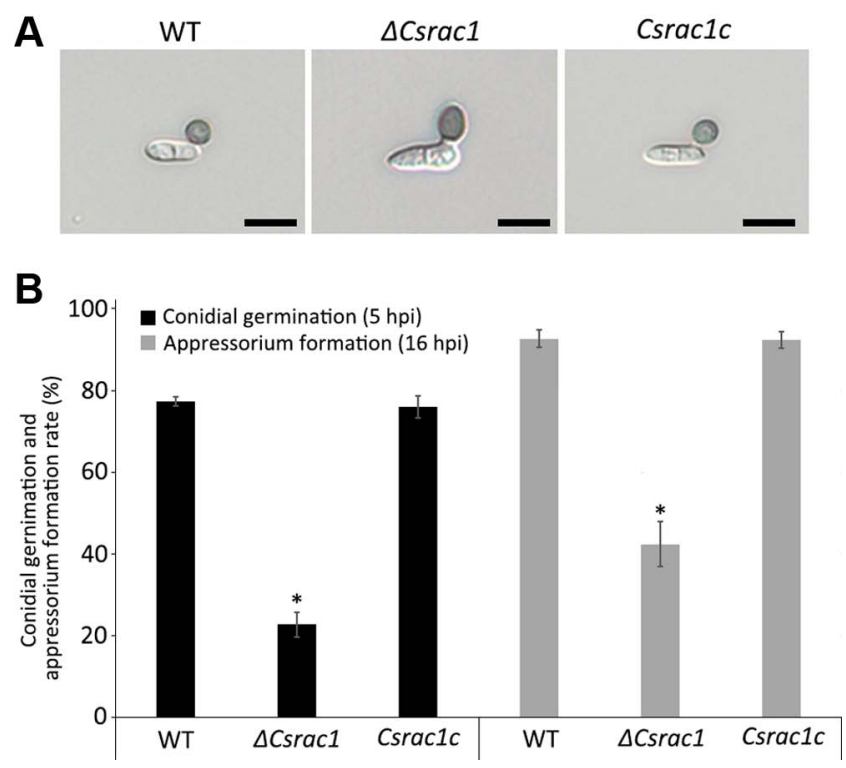

Fig. 5. Roles of CsRAC1 in conidial germination and appressorium formation on hydrophobic surface. (A) Observation of appressium formation. Photographs of appressoria were taken after $16 \mathrm{~h}$. Scale bars $=10 \mu \mathrm{m}$. (B) Evaluation of conidial germination and appressorium formation. Conidia obtained from 7-day-old oatmeal agar were placed on the hydrophobic surface of coverlsips and incubated for $10 \mathrm{~h}$ for germination and $16 \mathrm{~h}$ for appressorium formation. Significant difference $(*)$ was analyzed by Duncan's test $(P<0.05)$. 

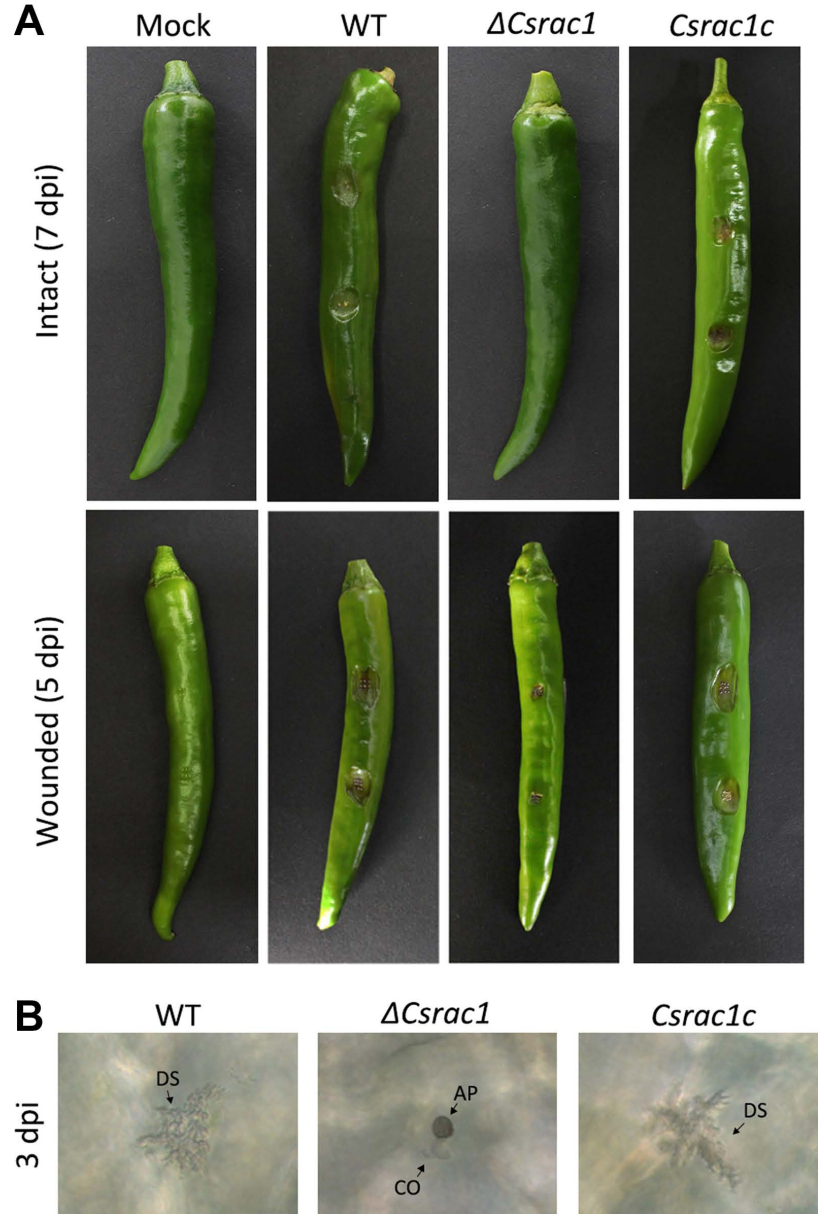

Fig. 6. Roles of CsRAC1 in anthrcnose development. (A) Pathogenicity assays. Conidial suspensions were inoculated onto intact and wounded pepper frutis, and incubated in a humid plastic box at $25^{\circ} \mathrm{C}$. Photographs of intact and wounded pepper fruits were taken after 7 and 5 days, respectively. (B) Observation of penetration. The photographs were taken after 3 days. CO, AP, and DS indicates conidium, appressorium, and dendroid structure, respectively. Scale bars $=20 \mu \mathrm{m}$.

involved in conidial germination and appressorium formation of C. scovillei.

Roles of CsRAC1 in anthracnose development. To determine the role of CsRACl in anthracnose development, we inoculated conidial suspensions onto intact pepper fruits. The $\triangle C$ Cracl was non-pathogenic, whereas the wild-type and $C$ sracl caused severe anthracnose disease after 7 days (Fig. 6A). This suggests that $C s R A C 1$ is essential for pathogenicity of $C$. scovillei. We further inoculated conidial suspensions onto wounded pepper fruits. The $\triangle C$ sracl was found to induce anthracnose disease with recued rate, compared to the wild-type and Csrac1c (Fig. 6A), suggesting that CsRAC1 is involved in post-infection of C. scovillei.
A

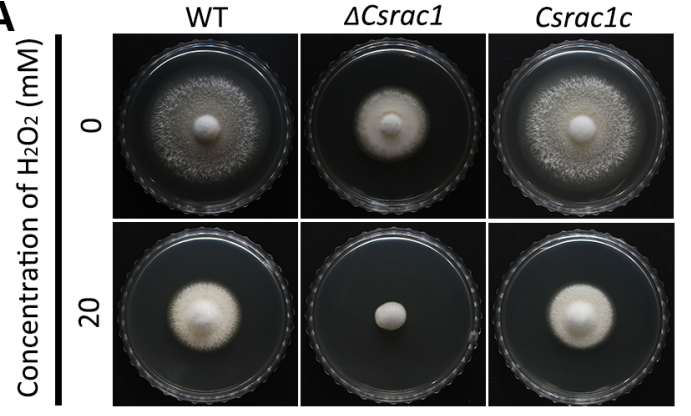

B
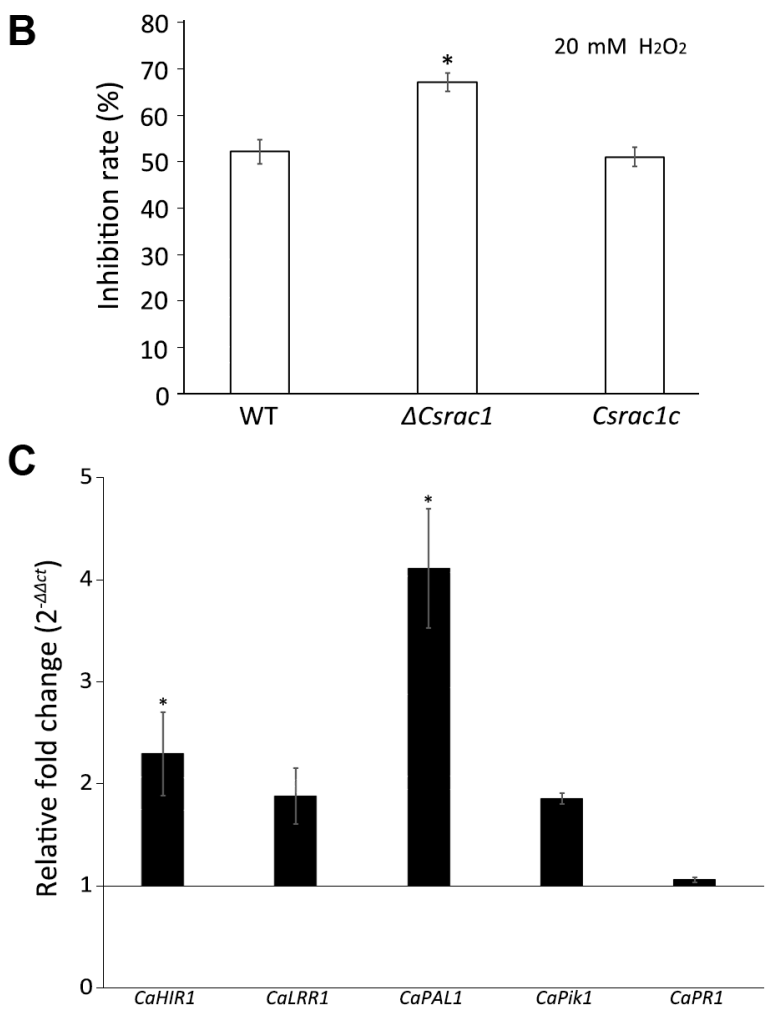

Fig. 7. Rols of CsRAC1 in tolerence to oxidative stress and expression of host-defense genes. (A, B) Mycelial growh on CMA contianing $20 \mathrm{mM} \mathrm{H}_{2} \mathrm{O}_{2}$. (A) The photogrpahs were taken after 5 days. (B) Inhibition rate of mycelial growth was evaluated after 5 days. (C) Expresion of host-defense genes. Total RNA was extracted from wounded pepper frutis infected by wild-type and $\triangle C s r a c l$ after $16 \mathrm{~h}$.

To investigate the role of CsRACl in penetration, we inoculated conidial suspensions onto intact pepper fruits. The result showed that the wild-type and Csraclc successfully penetrated and induced dendroid structures in host cuticles (Fig. 6B). However, although $\triangle C$ Sracl developed appressoria, it failed to penetrate (Fig. 6B). These results suggested that CSRAC1 is important for penetration and postinfection of $C$. scovillei.

Roles of $C S R A C 1$ in tolerance to oxidative stress and 
suppression of host-defense genes. In fungal-plant interactions, pathogens experience oxidative stress due to reactive oxygen species produced by plant (Segal and Wilson, 2018). To test whether CsRAC1 is involved in tolerance to oxidative stress, we evaluated mycelial growth on CMA containing $20 \mathrm{mM} \mathrm{H}_{2} \mathrm{O}_{2}$. The inhibition rate of mycelial growth was $67.2 \pm 2.0 \%$ in $\triangle C s r a c l$, compared to $52.2 \pm 2.6 \%$ in wild-type and $51.3 \pm 2.1 \%$ in Csaclc (Fig. 7A and B). This suggested that CsRACl contributes to tolerance to oxidative stress. We further evaluated expressions of host-defense genes in wounded pepper fruits infected by $\triangle C s r a c 1$. Result showed that expression levels of CaPAL1 and CaHIR1 were greatly increased in pepper fruits infected by $\triangle C s r a c 1$, compared that by wild-type and Csraclc (Fig. 7C).

\section{Discussion}

Anthracnose disease caused by the genus Colletotrichum leads to a huge economic loss worldwide (Cannon et al., 2012). Although the foliar anthracnose by several Colletotrichum species, including C. orbiculare, C. gloeosporioides, $C$. higginsianum, and $C$. graminicola, have been extensively studied (Gan et al., 2013; Irieda et al., 2019; O'Connell et al., 2012), the molecular mechanisms underlying Colletotrichum-fruits interaction are still unknown ( Fu et al., 2021). Therefore, we initiated functional genomics research on a pepper fruit anthracnose fungus $C$. scovillei (Fu et al., 2021; Han et al., 2016; Shin et al., 2019). Different to many other fungal pathogens which directly penetrate to the host cuticle layer, C. scovillei firstly penetrates the host wax layer and then developed highly branched hyphae in the cuticle layer, with an appearance of a dendroid structure (Fu et al., 2021). To study the anthracnose development on pepper fruits by $C$. scovillei, we decided to study a small GTPase RAC1, which was demonstrated to play important roles in fungal morphological development and appressorium-mediated penetration in several plant pathogenic fungi (Chen et al., 2008; Mahlert et al., 2006; Nesher et al., 2011; Rolke and Tudzynski, 2008; Tian et al., 2015; Virag et al., 2007). To investigate the CsRAC1, we firstly preformed analysis of phylogenetic relationship and domain prediction, which implicated that amino acid sequences of RAC1 GTPases are conserved among evolutionarily distant fungi.

Targeted deletion of CsRAC1 resulting in a mutant $(\triangle C \operatorname{sracl})$ significantly reduced mycelial growth on nutrient-rich and -depleted medium (Fig. 3A and B). Further analysis of hyphal septation indicated that distance between hyphal compartments is significantly shorter than that of wild-type and Csraclc (Fig. 3C and D). These results suggest that CsRAC1 is involved in hyphal growth and septation. Consistently, the association between the RAC1 GTPase and fungal growth was reported previously (Chen et al., 2008; Tian et al., 2015). In M. grisea, the Mgracl deletion mutant exhibited reduced mycelial growth, frequent branching, and curly tips in mycelia (Chen et al., 2008). In $U$. maydis, GTP-bound Rac1 was suggested to activate Cla4 to trigger cell wall extension at hyphal tip (Mahlert et al., 2006).

Deletion of CsRACl caused defects in fungal developments of $C$. scovillei. The $\Delta C s r a c l$ was significantly defective in conidiation, compared to the wild-type (Fig. 4), suggesting that CsRAC1 is associated with conidiation of $C$. scovillei. Notably, the conidia produced by $\triangle C s r a c l$ were morphologically abnormal, compared to that of wild-type (Fig. 4). Defect in conidiation was also found in deletion of Racl homologs in $M$. grisea and $V$. dahliae (Chen et al., 2008; Tian et al., 2015). The conidia produced by Racl deletion mutant in $M$. grisea and $V$. dahliae were elongated and round shape, respectively (Chen et al., 2008; Tian et al., 2015). These data suggest that $C s R A C l$ homologs play critical roles in conidiation. Our further analysis revealed that the abnormally-shaped conidia from $\triangle C s r a c l$ were reduced in conidial germination and appressorium formation in response to a hydrophobic surface (Fig. 5). Moreover, the appressoria generated by $\triangle C s r a c l$ conidia were larger in size, compared to those of wild-type (Fig. 5). Considering that RAC1 GTPase triggers reorganization of actin cytoskeleton (Moldovan et al., 1999), the CsRACl may regulate actin dynamics during appressorium development in C. scovillei.

Deletion of CsRAC1 significantly reduced capability to cause anthracnose on pepper fruits. $\triangle C s r a c l$ was completely defective in appressorium-mediated penetration (Fig. $6 \mathrm{~A}$ and $\mathrm{B})$. Although the appressoria formed by $\Delta$ Csracl were normal in morphology, they were unable to penetrate host cuticle (Fig. 6B). Previous studies revealed that the RAC1 functions to activate NOX complex (Chen et al., 2008; Ryder et al., 2013). During appressorium development, the NOX generates reactive oxygen species, which is involved in appressorium peg formation via remodeling septin-mediated cytoskeleton (Kim and Hwang, 2014). The $\triangle$ Csracl caused significantly recued lesions on wounded pepper fruits (Fig. 6A). Interestingly, the deletion mutant of CgRacl in C. gloeosporioides abolished plant infection in wounded host cells (Nesher et al., 2011). We speculate that CsRAC1 homologs may be involved in suppression of host-defense mechanism. This hypothesis is supported by significantly upregulation of two host-defense genes $(\mathrm{Ca}$ - 
PAL1 and CaHIR1) in host tissues infected by $\triangle$ Csracl, compared to wild-type (Fig. 7B). The CaPAL1 (phenylalanine ammonia-lyase) is known to play a role in salicylic acid-dependent signaling pepper in response to pathogens (Kim and Hwang, 2014). The CaHIR1 (hypersensitive induced reaction) positively regulates hypersensitive response cell death in plant infection (Jung and Hwang, 2007). We further tested mycelial growth in CMA containing $\mathrm{H}_{2} \mathrm{O}_{2}$ and found that $\triangle C s r a c l$ was more sensitive than wild-type under oxidative stress (Fig. 7A). These results reveal the fundamental roles of $C s R A C 1$ in anthracnose development of C. scovillei.

In summary, we characterized the functional roles of $C s$ $R A C 1$ in pepper fruit anthracnose fungus $C$. scovillei. Deletion of $C s R A C l$ caused pleiotropic defects in most stages of fungal growth, developments, and pathogenicity, including mycelial growth, conidiation, conidium morphology, conidial germination, appressorium formation, appressorium penetration, and post-infection of $C$. scovillei. These results suggest that $C s R A C 1$ plays essential roles in fungal growth, development, and pathogenicity during anthracnose by $C$. scovillei. Our results contribute to a better understanding of anthracnose disease development on fruits.

\section{Conflicts of Interest}

No potential conflict of interest relevant to this article was reported.

\section{Acknowledgments}

This study was supported by a research grant of Kangwon National University in 2018.

\section{References}

Ali, A., Bordoh, P. K., Singh, A., Siddiqui, Y. and Droby, S. 2016. Post-harvest development of anthracnose in pepper (Capsicum spp): etiology and management strategies. Crop Prot. 90:132141.

Barthelmes, K., Ramcke, E., Kang, H.-S., Sattler, M. and Itzen, A. 2020. Conformational control of small GTPases by AMPylation. Proc. Natl. Acad. Sci. U. S. A. 117:5772-5781.

Caires, N. P., Pinho, D. B., Souza, J., Silva, M. A., Lisboa, D. O., Pereira, O. L. and Furtado, G. Q. 2014. First report of anthracnose on pepper fruit caused by Colletotrichum scovillei in Brazil. Plant Dis. 98:1437.

Cannon, P. F., Damm, U., Johnston, P. R. and Weir, B. S. 2012. Colletotrichum: current status and future directions. Stud. Mycol. 73:181-213.

Chen, J., Zheng, W., Zheng, S., Zhang, D., Sang, W., Chen, X.,
Li, G., Lu, G. and Wang, Z. 2008. Rac1 is required for pathogenicity and Chm1-dependent conidiogenesis in rice fungal pathogen Magnaporthe grisea. PLoS Pathog. 4:e1000202.

Cherfils, J. and Zeghouf, M. 2013. Regulation of small GTPases by GEFs, GAPs, and GDIs. Physiol. Rev. 93:269-309.

Choi, J., Kim, Y., Kim, S., Park, J. and Lee, Y.-H. 2009. MoCRZ1, a gene encoding a calcineurin-responsive transcription factor, regulates fungal growth and pathogenicity of Magnaporthe oryzae. Fungal Genet. Biol. 46:243-254.

Egan, M. J., Wang, Z.-Y., Jones, M. A., Smirnoff, N. and Talbot, N. J. 2007. Generation of reactive oxygen species by fungal NADPH oxidases is required for rice blast disease. Proc. Natl. Acad. Sci. U. S. A. 104:11772-11777.

Food and Agriculture Organization of the United Nations. 2021. FAOSTAT. URL http://www.fao.org/faostat/en/\#data/QC/ visualize [3 November 2021].

Fu, T., Han, J.-H., Shin, J.-H., Song, H., Ko, J., Lee, Y.-H., Kim, K.-T. and Kim, K. S. 2021. Homeobox transcription factors are required for fungal development and the suppression of host defense mechanisms in the Colletotrichum scovilleipepper pathosystem. mBio 12:e162021.

Fu, T., Kim, J.-O., Han, J.-H., Gumilang, A., Lee, Y.-H. and Kim, K. S. 2018. A small GTPase RHO2 plays an important role in pre-infection development in the rice blast pathogen Magnaporthe oryzae. Plant Pathol. J. 34:470-479.

Fu, T., Park, G.-C., Han, J. H., Shin, J.-H., Park, H.-H. and Kim, K. S. 2019. MoRBP9 encoding a ran-binding protein microtubule-organizing center is required for asexual reproduction and infection in the rice blast pathogen Magnaporthe oryzae. Plant Pathol. J. 35:564-574.

Gan, P., Ikeda, K., Irieda, H., Narusaka, M., O'Connell, R. J., Narusaka, Y., Takano, Y., Kubo, Y. and Shirasu, K. 2013. Comparative genomic and transcriptomic analyses reveal the hemibiotrophic stage shift of Colletotrichum fungi. New Phytol. 197:1236-1249.

Giacomin, R. M., de Fátima Ruas, C., Moreira, A. F. P., Guidone, G. H. M., Baba, V. Y., Rodrigues, R. and Gonçalves, L. S. A. 2020. Inheritance of anthracnose resistance (Colletotrichum scovillei) in ripe and unripe Capsicum annuum fruits. J. Phytopathol. 168:184-192.

Gong, T., Liao, Y., He, F., Yang, Y., Yang, D.-D., Chen, X.-D. and Gao, X.-D. 2013. Control of polarized growth by the Rho family GTPase Rho4 in budding yeast: requirement of the N-terminal extension of Rho4 and regulation by the Rho GTPase-activating protein Bem2. Eukaryot. Cell 12:368-377.

Han, J.-H., Chon, J.-K., Ahn, J.-H., Choi, I.-Y., Lee, Y.-H. and Kim, K. S. 2016. Whole genome sequence and genome annotation of Colletotrichum acutatum, causal agent of anthracnose in pepper plants in South Korea. Genom. Data 8:45-46.

Han, J.-H., Lee, H.-M., Shin, J.-H., Lee, Y.-H. and Kim, K. S. 2015. Role of the MoYAK1 protein kinase gene in Magnaporthe oryzae development and pathogenicity. Environ. Microbiol. 17:4672-4689.

Han, J.-H., Shin, J.-H., Lee, Y.-H. and Kim, K. S. 2018. Distinct 
roles of the YPEL gene family in development and pathogenicity in the ascomycete fungus Magnaporthe oryzae. Sci. Rep. 8:14461.

Harris, S. D. 2011. Cdc42/Rho GTPases in fungi: variations on a common theme. Mol. Microbiol. 79:1123-1127.

Irieda, H., Inoue, Y., Mori, M., Yamada, K., Oshikawa, Y., Saitoh, H., Uemura, A., Terauchi, R., Kitakura, S., Kosaka, A., Singkaravanit-Ogawa, S. and Takano, Y. 2019. Conserved fungal effector suppresses PAMP-triggered immunity by targeting plant immune kinases. Proc. Natl. Acad. Sci. U. S. A. 116:496-505.

Jung, H. W. and Hwang, B. K. 2007. The leucine-rich repeat (LRR) protein, CaLRR1, interacts with the hypersensitive induced reaction (HIR) protein, CaHIR1, and suppresses cell death induced by the CaHIR1 protein. Mol. Plant Pathol. 8:503-514.

Karnoub, A. E., Symons, M., Campbell, S. L. and Der, C. J. 2004. Molecular basis for Rho GTPase signaling specificity. Breast Cancer Res. Treat. 84:61-71.

Khalimi, K., Darmadi, A. A. K. and Suprapta, D. N. 2019. First report on the prevalence of Colletotrichum scovillei associated with anthracnose on chili pepper in Bali, Indonesia. Int. J. Agric. Biol. 22:363-368.

Kim, D. S. and Hwang, B. K. 2014. An important role of the pepper phenylalanine ammonia-lyase gene (PAL1) in salicylic acid-dependent signalling of the defence response to microbial pathogens. J. Exp. Bot. 65:2295-2306.

Kim, S., Park, M., Yeom, S.-I., Kim, Y.-M., Lee, J. M., Lee, H.A., Seo, E., Choi, J., Cheong, K., Kim, K.-T., Jung, K., Lee, G.-W., Oh, S.-K., Bae, C., Kim, S.-B., Lee, H.-Y., Kim, S.-Y., Kim, M.-S., Kang, B.-C., Jo, Y. D., Yang, H.-B., Jeong, H.J., Kang, W.-H., Kwon, J.-K., Shin, C., Lim, J. Y., Park, J. H., Huh, J. H., Kim, J.-S., Kim, B.-D., Cohen, O., Paran, I., Suh, M. C., Lee, S. B., Kim, Y.-K., Shin, Y., Noh, S.-J., Park, J., Seo, Y.-S., Kwon, S.-Y., Kim, H. A., Park, J. M., Kim, H.-J., Choi, S.-B., Bosland, P. W., Reeves, G., Jo, S.-H., Lee, B.-W., Cho, H.-T., Choi, H.-S., Lee, M.-S., Yu, Y., Choi, Y. D., Park, B.-S., van Deynze, A., Ashrafi, H., Hill, T., Kim, W. T., Pai, H.-S., Ahn, H. K., Yeam, I., Giovannoni, J. J., Rose, J. K. C., Sørensen, I., Lee, S.-J., Kim, R. W., Choi, I.-Y., Choi, B.-S., Lim, J.-S., Lee, Y.-H. and Choi, D. 2014. Genome sequence of the hot pepper provides insights into the evolution of pungency in Capsicum species. Nat. Genet. 46:270-278.

Liao, C.-Y., Chen, M.-Y., Chen, Y.-K., Kuo, K.-C., Chung, K.-R. and Lee, M.-H. 2012. Formation of highly branched hyphae by Colletotrichum acutatum within the fruit cuticles of Capsicum spp. Plant Pathol. 61:262-270.

Mahlert, M., Leveleki, L., Hlubek, A., Sandrock, B. and Bölker, M. 2006. Rac1 and Cdc42 regulate hyphal growth and cytokinesis in the dimorphic fungus Ustilago maydis. Mol. Microbiol. 59:567-578.

Moldovan, L., Irani, K., Moldovan, N. I., Finkel, T. and Goldschmidt-Clermont, P. J. 1999. The actin cytoskeleton reorganization induced by Rac1 requires the production of superox- ide. Antioxid. Redox Signal. 1:29-43.

Nesher, I., Minz, A., Kokkelink, L., Tudzynski, P. and Sharon, A. 2011. Regulation of pathogenic spore germination by CgRac1 in the fungal plant pathogen Colletotrichum gloeosporioides. Eukaryot. Cell 10:1122-1130.

O'Connell, R. J., Thon, M. R., Hacquard, S., Amyotte, S. G., Kleemann, J., Torres, M. F., Damm, U., Buiate, E. A., Epstein, L., Alkan, N., Altmüller, J., Alvarado-Balderrama, L., Bauser, C. A., Becker, C., Birren, B. W., Chen, Z., Choi, J., Crouch, J. A., Duvick, J. P., Farman, M. A., Gan, P., Heiman, D., Henrissat, B., Howard, R. J., Kabbage, M., Koch, C., Kracher, B., Kubo, Y., Law, A. D., Lebrun, M.-H., Lee, Y.-H., Miyare, I., Moore, N., Neumann, U., Nordström, K., Panaccione, D. G., Panstruga, R., Place, M., Proctor, R. H., Prusky, D., Rech, G., Reinhardt, R., Rollins, J. A., Rounsley, S., Schardl, C. L., Schwartz, D. C., Shenoy, N., Shirasu, K., Sikhakolli, U. R., Stüber, K., Sukno, S. A., Sweigard, J. A., Takano, Y., Takahara, H., Trail, F., van der Does, H. C., Voll, L. M., Will, I., Young, S., Zeng, Q., Zhang, J., Zhou, S., Dichman, M. B., Schulze-Lefert, P., Ver Loren van Themaat, E., Ma, L. J. and Vaillancourt, L. J. 2012. Lifestyle transitions in plant pathogenic Colletotrichum fungi deciphered by genome and transcriptome analyses. Nat. Genet. 44:1060-1065.

Oo, M. M., Lim, G., Jang, H. A. and Oh, S.-K. 2017. Characterization and pathogenicity of new record of anthracnose on various chili varieties caused by Colletotrichum scovillei in Korea. Mycobiology 45:184-191.

Oo, M. M. and Oh, S.-K. 2016. Chilli anthracnose (Colletotrichum spp.) disease and its management approach. Korean J. Agric. Sci. 43:153-162.

Peres, N. A., Timmer, L. W., Adaskaveg, J. E. and Correll, J. C. 2005. Lifestyles of Colletotrichum acutatum. Plant Dis. 89:784-796.

Robinson, N. G. G., Guo, L., Imai, J., Toh-e, A., Matsui, Y. and Tamanoi, F. 1999. Rho3 of Saccharomyces cerevisiae, which regulates the actin cytoskeleton and exocytosis, is a GTPase which interacts with Myo2 and Exo70. Mol. Cell. Biol. 19:3580-3587.

Rolke, Y. and Tudzynski, P. 2008. The small GTPase Rac and the p21-activated kinase Cla4 in Claviceps purpurea: interaction and impact on polarity, development and pathogenicity. Mol. Microbiol. 68:405-423.

Ryder, L. S., Dagdas, Y. F., Mentlak, T. A., Kershaw, M. J., Thornton, C. R., Schuster, M., Chen, J., Wang, Z. and Talbot, N. J. 2013. NADPH oxidases regulate septin-mediated cytoskeletal remodeling during plant infection by the rice blast fungus. Proc. Natl. Acad. Sci. U. S. A. 110:3179-3184.

Schmidt, A., Bickle, M., Beck, T. and Hall, M. N. 1997. The yeast phosphatidylinositol kinase homolog TOR2 activates RHO1 and RHO2 via the exchange factor ROM2. Cell 88:531-542.

Segal, L. M. and Wilson, R. A. 2018. Reactive oxygen species metabolism and plant-fungal interactions. Fungal Genet. Biol. 110:1-9.

Shin, J.-H., Han, J.-H., Park, H.-H., Fu, T. and Kim, K. S. 2019. 
Optimization of polyethylene glycol-mediated transformation of the pepper anthracnose pathogen Colletotrichum scovillei to develop an applied genomics approach. Plant Pathol. J. 35:575-584.

Smithers, C. C. and Overduin, M. 2016. Structural mechanisms and drug discovery prospects of Rho GTPases. Cells 5:26.

Tian, H., Zhou, L., Guo, W. and Wang, X. 2015. Small GTPase Rac1 and its interaction partner Cla4 regulate polarized growth and pathogenicity in Verticillium dahliae. Fungal Genet. Biol. 74:21-31.

Toporek, S. M. and Keinath, A. P. 2020. First report of Colletotrichum scovillei causing anthracnose fruit rot on pepper in South Carolina, United States. Plant Dis. 105:1222.
Van Aelst, L. and D'Souza-Schorey, C. 1997. Rho GTPases and signaling networks. Genes Dev. 11:2295-2322.

Virag, A., Lee, M. P., Si, H. and Harris, S. D. 2007. Regulation of hyphal morphogenesis by $c d c 42$ and racl homologues in Aspergillus nidulans. Mol. Microbiol. 66:1579-1596.

Yoshida, S., Bartolini, S. and Pellman, D. 2009. Mechanisms for concentrating Rho1 during cytokinesis. Genes Dev. 23:810823.

Yu, J.-H., Hamari, Z., Han, K.-H., Seo, J.-A., Reyes-Domínguez, Y. and Scazzocchio, C. 2004. Double-joint PCR: a PCRbased molecular tool for gene manipulations in filamentous fungi. Fungal Genet. Biol. 41:973-981. 